\title{
Xylitol prevents NEFA-induced insulin resistance in rats
}

\author{
P. Kishore $\cdot$ S. Kehlenbrink $\cdot$ M. Hu $\cdot$ K. Zhang • \\ R. Gutierrez-Juarez • S. Koppaka • M. R. El-Maghrabi • \\ M. Hawkins
}

Received: 12 December 2011 / Accepted: 6 February 2012/Published online: 30 March 2012

(C) Springer-Verlag 2012

\begin{abstract}
Aims/hypothesis Increased NEFA levels, characteristic of type 2 diabetes mellitus, contribute to skeletal muscle insulin resistance. While NEFA-induced insulin resistance was formerly attributed to decreased glycolysis, it is likely that glucose transport is the rate-limiting defect. Recently, the plant-derived sugar alcohol xylitol has been shown to have favourable metabolic effects in various animal models. Furthermore, its derivative xylulose 5-phosphate may prevent NEFA-induced suppression of glycolysis. We therefore examined whether and how xylitol might prevent NEFAinduced insulin resistance.

Methods We examined the ability of xylitol to prevent NEFA-induced insulin resistance. Sustained $\sim 1.5$-fold elevations in NEFA levels were induced with Intralipid/heparin infusions during 5 h euglycaemic-hyperinsulinaemic clamp studies in 24 conscious non-diabetic Sprague-Dawley rats, with or without infusion of xylitol.

Results Intralipid infusion reduced peripheral glucose uptake by $\sim 25 \%$, predominantly through suppression of glycogen synthesis. Co-infusion of xylitol prevented the NEFAinduced decreases in both glucose uptake and glycogen synthesis. Although glycolysis was increased by xylitol infusion alone, there was minimal NEFA-induced suppression of glycolysis, which was not affected by co-infusion of xylitol.
\end{abstract}

P. Kishore $\cdot$ S. Kehlenbrink $\cdot$ M. Hu $\cdot$ K. Zhang $\cdot$

R. Gutierrez-Juarez $\cdot$ S. Koppaka $\cdot$ M. Hawkins $(\square)$

Diabetes Research Center, Albert Einstein College of Medicine,

1300 Morris Park Ave, Belfer 709,

Bronx, NY 10461, USA

e-mail: meredith.hawkins@einstein.yu.edu

M. R. El-Maghrabi

Department of Physiology and Biophysics,

Stony Brook University,

Stony Brook, NY, USA
Conclusions/interpretation We conclude that xylitol prevented NEFA-induced insulin resistance, with favourable effects on glycogen synthesis accompanying the improved insulin-mediated glucose uptake. This suggests that this pentose sweetener has beneficial insulin-sensitising effects.

Keywords Insulin resistance - NEFA · Type 2 diabetes mellitus $\cdot$ Xylitol
Abbreviations
Fru-2,6- $\mathrm{P}_{2} \quad$ Fructose 2,6-bisphosphate
GIR Glucose infusion rate
$\mathrm{Xu}-5-\mathrm{P} \quad$ Xylulose 5-phosphate

\section{Introduction}

Increased circulating levels of NEFA contribute to the pathogenesis and progression of type 2 diabetes at least in part by impairing peripheral insulin sensitivity [1]. Multiple mechanisms are likely to be involved in NEFA-induced insulin resistance, including insulin-signalling defects and low-grade inflammation [2,3]. While Randle's hypothesis proposed that increased NEFA availability results in impairments in the activities of key enzymes of glucose oxidation, subsequent reports suggest that the rate-limiting step resides at the level of glucose transport [4]. Xylitol and its derivatives have been shown to have favourable metabolic effects in rodents and humans [5-8], although it remains to be determined whether they have insulin-sensitising effects independent of their effects on body composition. As xylulose 5-phosphate (Xu5-P) increases the formation of fructose 2,6-bisphosphate (Fru-2,6- $\mathrm{P}_{2}$ ) [9], we predicted that xylitol infusion would enhance glycolytic flux. Therefore, we infused xylitol during insulin clamp studies in normal rats in the presence of 
increased NEFA to determine whether xylitol could reverse NEFA-induced insulin resistance, and whether stimulation of glycolysis might be responsible for its effects. Hence, elevating NEFA acid levels transiently with lipid emulsion provides an acute model of insulin resistance in which the insulinsensitising effects of xylitol could be formally tested.

\section{Methods}

Animals

Twenty-four male Sprague-Dawley rats (Charles River Laboratories, Wilmington, MA, USA) were studied 5-7 days following central catheter placement, as previously described [10]. The National Institutes of Health's principles of laboratory care were followed, and the study was approved by Einstein's Institutional Animal Care and Use Committee.

\section{Clamp studies}

Studies were performed in awake unstressed rats fasted for 6 h. Euglycaemic-hyperinsulinaemic $\left(18 \mathrm{mU} \mathrm{kg}^{-1} \mathrm{~min}^{-1}\right)$ clamp studies were performed with $\left[3-{ }^{3} \mathrm{H}\right]$ glucose infusion (New England Nuclear, Boston, MA, USA; 2.96× $10^{5} \mathrm{~Bq}$ bolus, $1.48 \times 10^{4} \mathrm{~Bq} / \mathrm{min}$ ) [10]. A variable infusion of $25 \%$ glucose (wt/vol.) was started at $t=0$ and adjusted every 5-10 min, maintaining basal plasma glucose concentrations $(\sim 7.0 \mathrm{mmol} / \mathrm{l})$. Clamp studies were performed under the following conditions in four groups of age- and weight-matched rats: (1) Intralipid, (2) Intralipid/xylitol, (3) xylitol control and (4) saline control.

Intralipid A continuous infusion of lipid emulsion (Intralipid 10\%, Baxter Healthcare, Deerfield, IL, USA; 1:2 suspension with heparinised saline $[154 \mathrm{mmol} / \mathrm{l} \mathrm{NaCl}]$ ) was maintained for $5 \mathrm{~h}(1.5 \mathrm{ml} / \mathrm{h} ; n=6)$ throughout the clamp studies.

Intralipid/xylitol Continuous infusions of lipid emulsion at $1.5 \mathrm{ml} / \mathrm{h}$ (as above) were maintained for $5 \mathrm{~h}$ during the clamp studies, with the addition of xylitol infusion (15 $\left.\mu \mathrm{mol} \mathrm{kg} \mathrm{kin}^{-1}\right)$ from $t=-1$ to $5 \mathrm{~h}(n=7)$.

Xylitol control Xylitol alone $\left(15 \mu \mathrm{mol} \mathrm{kg}{ }^{-1} \mathrm{~min}^{-1}\right)$ was infused from $t=-1$ to $5 \mathrm{~h}(n=5)$ during the clamp studies.

Saline control Clamp studies over $5 \mathrm{~h}$, with saline infusion from $t=-1$ to $5 \mathrm{~h}$, were performed in six rats.

Sampling and measurements Plasma samples were obtained at $10 \mathrm{~min}$ intervals throughout the studies for determination of $\left[{ }^{3} \mathrm{H}\right]$ glucose-specific activity. Samples for measurement of plasma insulin and NEFA concentrations were obtained hourly from $t=-1$ to $5 \mathrm{~h}$. The total volume of blood sampled was $\sim 4.0 \mathrm{ml} /$ study. To prevent volume depletion and anaemia, approximately $6.0 \mathrm{ml}$ of fresh blood (obtained by heart puncture from a littermate) and heparinised saline $(10 \mathrm{U} / \mathrm{ml})$ was infused (1:1 [vol./vol.]). Rectus abdominal muscle samples were obtained at the end of the studies as previously described [10], and stored at $-80^{\circ} \mathrm{C}$.

\section{Analytical procedures}

Plasma-specific activity and rates of glucose uptake, glycolysis and glycogen synthesis were measured/calculated as previously described [10]. Plasma glucose was measured by the glucose oxidase method, plasma insulin by radioimmunoassay and plasma NEFA by enzymatic colorimetry, as previously described [10]. Fru-2,6- $\mathrm{P}_{2}$ levels were measured in triplicate using the 6-phosphofructo-1-kinase activation assay [11]. All values are presented as mean \pm SE. Comparisons between groups were made using repeated-measures ANOVA and Student's $t$ tests, where appropriate.

\section{Results}

Animal characteristics

Mean animal body weights and baseline plasma glucose and NEFA concentrations were similar in all groups $(p>0.1)$ (Table 1).

Table 1 Comparison of average rodent body weight, plasma glucose and plasma NEFA during the $5 \mathrm{~h}$ clamp studies in the four groups

\begin{tabular}{|c|c|c|c|c|c|c|c|}
\hline \multirow[t]{2}{*}{ Group } & \multirow[t]{2}{*}{ Body weight (g) } & \multicolumn{3}{|c|}{ Glucose (mmol/1) } & \multicolumn{3}{|c|}{ NEFA (mmol/l) } \\
\hline & & Basal & $60-120 \mathrm{~min}$ & 240-300 min & Basal & $60-120 \mathrm{~min}$ & $240-300 \mathrm{~min}$ \\
\hline Xylitol control & $331 \pm 18$ & $8.45 \pm 0.6$ & $6.66 \pm 0.2$ & $7.17 \pm 0.1$ & $0.293 \pm 0.012$ & $0.218 \pm 0.028$ & $0.210 \pm 0.032$ \\
\hline Intralipid/xylitol & $337 \pm 12$ & $8.05 \pm 0.4$ & $7.07 \pm 0.1$ & $7.14 \pm 0.1$ & $0.333 \pm 0.054$ & $0.460 \pm 0.039$ & $0.408 \pm 0.024$ \\
\hline Intralipid & $331 \pm 15$ & $9.06 \pm 0.7$ & $6.77 \pm 0.1$ & $7.07 \pm 0.1$ & $0.317 \pm 0.031$ & $0.553 \pm 0.126$ & $0.376 \pm 0.019$ \\
\hline Saline control & $339 \pm 23$ & $8.37 \pm 0.3$ & $6.60 \pm 0.1$ & $6.72 \pm 0.1$ & $0.317 \pm 0.033$ & $0.2025 \pm 0.005$ & $0.194 \pm 0.073$ \\
\hline
\end{tabular}


Insulin clamp conditions

Plasma glucose concentrations were maintained at basal levels and plasma insulin levels were maintained constant at $\sim 3,472 \mathrm{pmol} / 1$ throughout all studies. Plasma-specific activity was constant in all studies. Plasma NEFA concentrations fell rapidly to $\sim 0.2 \mathrm{mmol} / 1$ during the saline and xylitol control studies in response to high insulin levels. Plasma NEFA concentrations were maintained at $\sim 50 \%$ above basal levels by Intralipid infusion and were comparable in the Intralipid and Intralipid/xylitol studies (Table 1).

Glucose uptake

Systemic insulin sensitivity was assessed by tracer-derived measures of glucose uptake and the glucose infusion rates
(GIRs) required to maintain euglycaemia during the clamp studies. Intralipid infusion alone resulted in significant decreases in glucose uptake by $\sim 3 \mathrm{~h}$, with $\sim 25 \%$ decreases observed by $5 \mathrm{~h}(4-5 \mathrm{~h}=35.9 \pm 1.7$ vs $1-2 \mathrm{~h}=48.6 \pm$ $2.8 \mathrm{mg} \mathrm{kg}^{-1} \mathrm{~min}^{-1} ; p=0.0053$ ) (Fig. 1a, b). Elevated NEFA levels also reduced GIR by $29 \%(4-5 \mathrm{~h}=25.1 \pm 1.1$ vs $1-2 \mathrm{~h}=35.6 \pm 1.3 \mathrm{mg} \mathrm{kg}^{-1} \mathrm{~min}^{-1} ; p=0.0006$, Fig. 1c, d), with half-maximal reductions in glucose uptake and GIR by $\sim 3.5 \mathrm{~h}$. In the saline control studies, there were no significant time-dependent decreases in GIR $(4-5 \mathrm{~h}=34.2$ \pm 1.9 vs $\left.1-2 \mathrm{~h}=37.5 \pm 1.5 \mathrm{mg} \mathrm{kg}^{-1} \mathrm{~min}^{-1} ; p=0.20\right)$ or glucose uptake $(4-5 \mathrm{~h}=37.5 \pm 2.3$ vs $1-2 \mathrm{~h}=41.9 \pm$ $\left.1.3 \mathrm{mg} \mathrm{kg}^{-1} \min ^{-1} ; p=0.13\right)$. There was also no effect of xylitol alone on GIR $(4-5 \mathrm{~h}=31.9 \pm 4.8$ vs $1-2 \mathrm{~h}=34.1 \pm$ $\left.2.4 \mathrm{mg} \mathrm{kg}^{-1} \min ^{-1} ; p=0.66\right)$ or glucose uptake $(4-5 \mathrm{~h}=42.5$ \pm 4.7 vs $\left.1-2 \mathrm{~h}=46.3 \pm 2.7 \mathrm{mg} \mathrm{kg}^{-1} \mathrm{~min}^{-1} ; p=0.10\right)$. Despite a

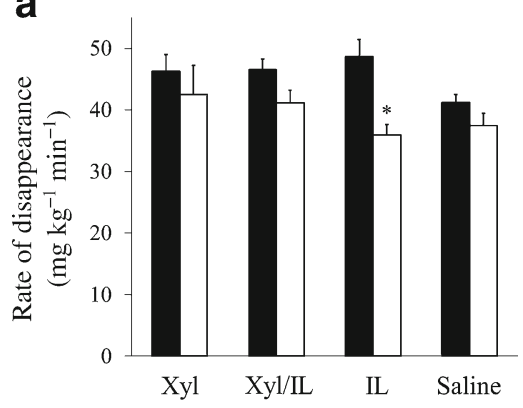

d

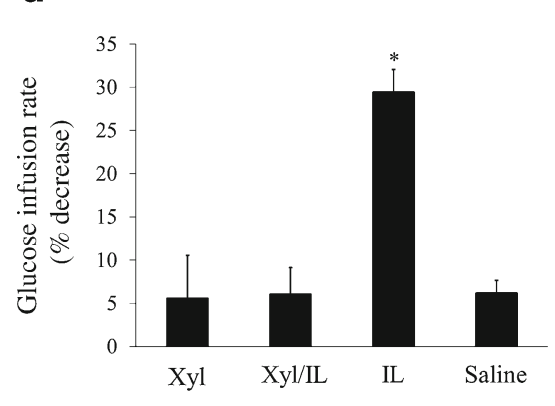

b

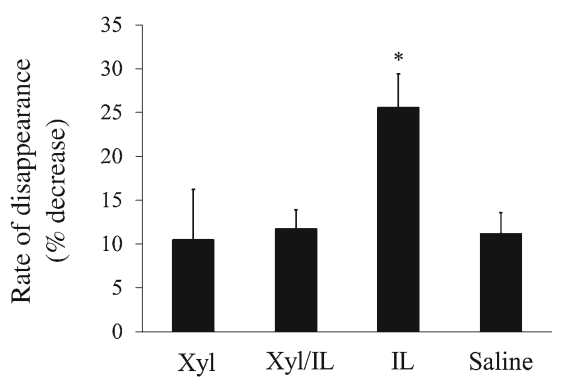

e

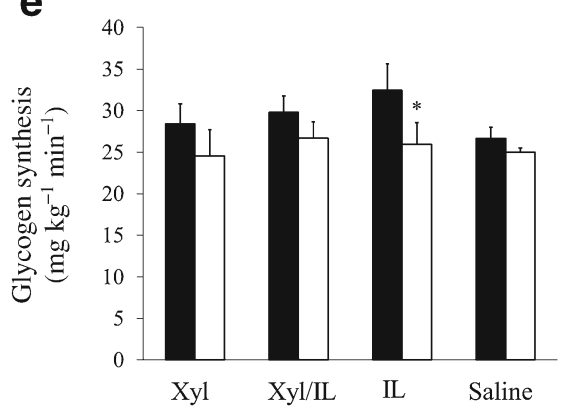

C

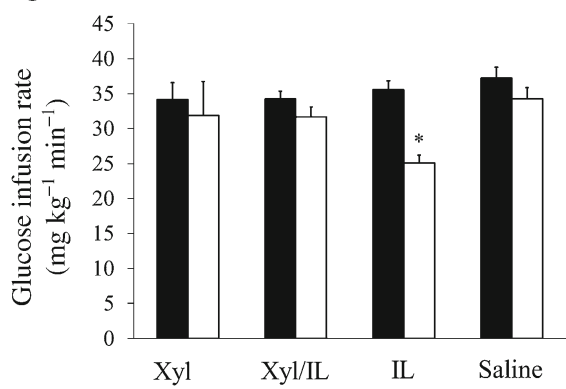

f

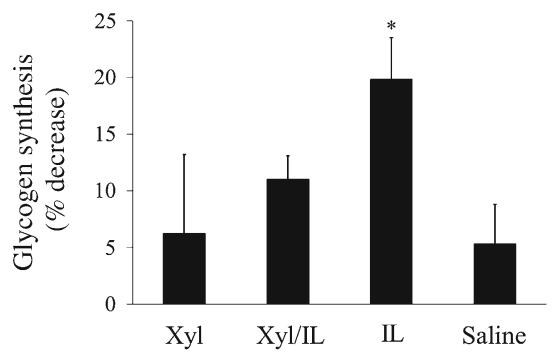

g

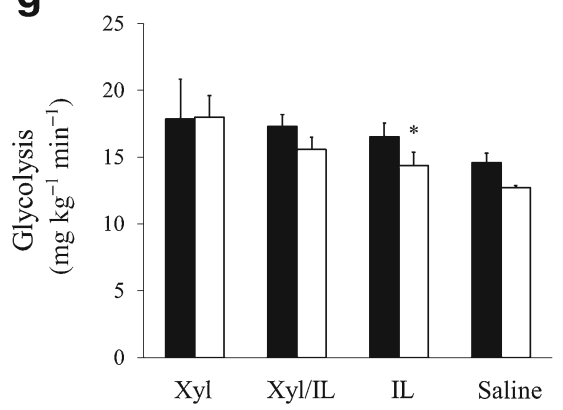

Fig. 1 Rate of glucose disappearance (i.e. glucose uptake) (a, b), GIR $(\mathbf{c}, \mathbf{d})$, glycogen synthesis $(\mathbf{e}, \mathbf{f})$ and glycolysis $(\mathbf{g}, \mathbf{h})$ plotted during the initial 1-2 h (black bars) and final 4-5 h (white bars) of the euglycaemic-hyperinsulinaemic clamp studies, expressed in $\mathrm{mg} \mathrm{kg}^{-1} \mathrm{~min}^{-1}$ h

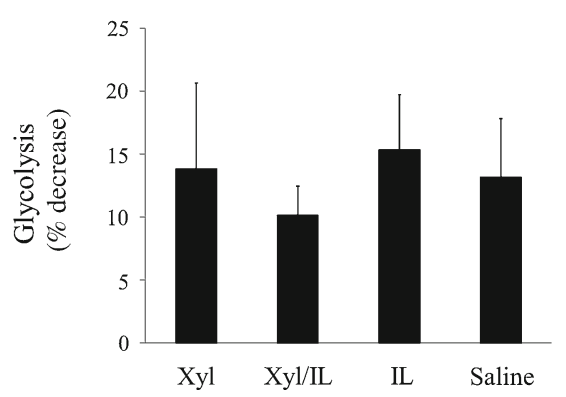

(a, $\mathbf{c}, \mathbf{e}, \mathbf{g})$ and as percentage change from the initial to final time period $(\mathbf{b}, \mathbf{d}, \mathbf{f}, \mathbf{h})$. All studies were performed for $5 \mathrm{~h}$ in the four groups: NEFA; saline; NEFA/xylitol; and xylitol. ${ }^{*} p<0.05$. IL, Intralipid (i.e. NEFA); Xyl, xylitol 
prolonged increases in NEFA, co-infusion of xylitol prevented reductions in GIR, and time-dependent effects on glucose uptake did not differ from the control groups (Intralipid/xylitol $=11.7 \pm 2.2 \%$ decrease; $p>0.99$ by ANOVA vs. saline $=11.2 \pm 2.4 \%$ and $x y l i t o l=10.5 \pm 5.8 \%$ ).

\section{Glycogen synthesis and glycolysis}

The decrease in glucose uptake in the NEFA studies was accounted for by reductions in rates of both glycogen synthesis $\left(4-5 \mathrm{~h}=25.9 \pm 2.6\right.$ vs $1-2 \mathrm{~h}=32.4 \pm 3.2 \mathrm{mg} \mathrm{kg}^{-1} \mathrm{~min}^{-1}$; $p=0.022$; Fig. 1e, f) and glycolysis $(4-5 \mathrm{~h}=13.9 \pm 1.1$ vs $1-$ $2 \mathrm{~h}=16.5 \pm 0.3 \mathrm{mg} \mathrm{kg}^{-1} \min ^{-1} ; p=0.042$; Fig. $\left.1 \mathrm{~g}, \mathrm{~h}\right)$. While infusion of xylitol alone induced a trend toward increased glycolysis compared with the saline studies, $(17.9 \pm 2.9$ vs $\left.14.5 \pm 0.8 \mathrm{mg} \mathrm{kg}^{-1} \mathrm{~min}^{-1}\right)$, the difference was not significant $(p=0.326)$. There were no reductions in glycogen synthesis in the saline or xylitol control studies. With co-infusion of xylitol and NEFA, glycogen synthesis and glycolysis did not differ from the control studies. Of note, given the tracer method used, requiring $\sim 1 \mathrm{~h}$ to achieve plasma equilibrium, possible early effects of NEFA and xylitol on glycolysis may have been underestimated. Hyperinsulinaemia resulted in approximately fivefold elevations in skeletal muscle Fru2,6- $\mathrm{P}_{2}$ levels following the saline studies, compared with fasting levels $(2.15 \pm 0.32$ vs $0.46 \pm 0.17 \mathrm{pmol} / \mathrm{mg}$, respectively), yet this effect of insulin was abolished by increased NEFA (Fru-2,6- $\mathrm{P}_{2}=0.66 \pm 0.10 \mathrm{pmol} / \mathrm{mg}$ ). The infusion of xylitol alone resulted in further elevations of Fru-2,6- $\mathrm{P}_{2}$ relative to those in saline studies $(3.31 \pm 0.02 \mathrm{pmol} / \mathrm{mg}, p<0.01)$. However, co-infusion of xylitol restored Fru-2,6- $\mathrm{P}_{2}$ to levels comparable with those in the saline control studies.

\section{Discussion}

These studies examined the metabolic effects of xylitol under hyperinsulinaemic conditions, while approximating the elevated NEFA levels observed in type 2 diabetes. Consistent with previous reports [12], increased NEFA availability in normal rats caused peripheral insulin resistance within $\sim 3.5 \mathrm{~h}$. Xylitol prevented the development of NEFA-induced insulin resistance.

A recent study reported that xylitol decreased visceral fat mass and reduced insulin levels in rats on a chronic high-fat diet [8]. As the effects of xylitol on visceral fat mass might have affected insulin action, the current model of acute NEFA-induced insulin resistance allowed us to examine the effects of xylitol on insulin sensitivity independent of body composition. Thus, these studies are the first comprehensive metabolic studies that include insulin clamps, and reveal beneficial peripheral insulin-sensitising effects of xylitol.
Elevated NEFA contribute to insulin resistance in humans including such mechanisms as insulin-signalling defects [2]. Specifically, NEFA are known to impair peripheral glucose uptake, which appears to be attributable, at least in part, to inhibition of glycogen synthesis [13]. In the current studies, xylitol prevented the NEFA-induced decreases in both glucose uptake and glycogen synthesis. Thus, xylitol appears to exert beneficial effects on peripheral insulin action in the face of increased NEFA availability, a hallmark of the metabolic syndrome. In addition, NEFAinduced inflammation may contribute to insulin resistance, probably through circulating factors [3, 14]. While not the focus of the current studies, xylitol may reduce inflammation [15], which might contribute to its systemic insulin-sensitising effects.

These studies also explored evolving theories regarding the role of glycolysis in NEFA-induced insulin resistance. The formation of hepatic Fru-2,6- $\mathrm{P}_{2}$ is regulated by Xu-5-Pdependent activation of protein phosphatase 2A [9]. Although xylitol alone increased Fru-2,6- $\mathrm{P}_{2}$ levels and caused an upward trend in glycolysis, rates of glycolysis remained unchanged with co-infusion of NEFA. Moreover, xylitol alone had no direct stimulatory effect on peripheral glucose uptake in these insulin-sensitive rats. Consistent with previous reports [4], these findings suggest that impaired glucose oxidation does not contribute importantly to NEFA-induced insulin resistance. As Xu5-P determines the transcription rates of various metabolic enzymes [10], preventing a decline in skeletal muscle Xu-5-P could contribute to the beneficial effects of xylitol on peripheral insulin action in the face of increased NEFA availability.

In summary, xylitol infusion during insulin clamp studies in normal rats prevented fatty-acid-induced insulin resistance, with favourable effects on glycogen synthesis and insulin-mediated glucose uptake. While earlier studies have suggested that xylitol may have metabolic benefits, these are the first studies to demonstrate insulin-sensitising effects of this compound in an acute model of insulin resistance and may highlight a promising therapeutic option for overcoming NEFAinduced insulin resistance.

Acknowledgments The authors wish to thank L. Rossetti (Albert Einstein College of Medicine) for his generous involvement, as well as B. Liu (Albert Einstein College of Medicine), R. Squeglia (Albert Einstein College of Medicine) and S. Lawrence (Albert Einstein College of Medicine) for excellent technical assistance.

Funding This work was supported by grants from the National Institutes of Health (DK48321, DK 45024 and DK69861, K23 RR023335 and P01-AG021654), the American Diabetes Association and the Albert Einstein Diabetes Research and Training Center (DK 20541). M. Hawkins is a Beeson Scholar of the American Federation of Aging Research. 
Contribution statement $\mathrm{PK}, \mathrm{MHa}$ and $\mathrm{SKe}$ wrote the manuscript. $\mathrm{MHu}$ and $\mathrm{KZ}$ performed the clamp studies. RE-M, MHu and $\mathrm{MH}$ performed the Fru-2,6- $\mathrm{P}_{2}$ measurements. All authors analysed and interpreted the data. MHa directed the studies and was involved in all aspects of study design, data analysis and composing the manuscript. All authors were involved in revising the manuscript critically for important content and approved the final version for publication.

Duality of interest The authors declare that there is no duality of interest associated with this manuscript.

\section{References}

1. Williams B (1994) Insulin resistance: the shape of things to come. Lancet 344:521-524

2. Boden G (2006) Fatty acid-induced inflammation and insulin resistance in skeletal muscle and liver. Curr Diab Rep 6:177-181

3. Olefsky JM, Glass CK (2010) Macrophages, inflammation, and insulin resistance. Annu Rev Physiol 72:219-246

4. Samuel VT, Petersen KF, Shulman GI (2010) Lipid-induced insulin resistance: unravelling the mechanism. Lancet 375:2267-2277

5. Chandramohan G, Ignacimuthu S, Pugalendi KV (2008) A novel compound from Casearia esculenta (Roxb.) root and its effect on carbohydrate metabolism in streptozotocin-diabetic rats. Eur J Pharmacol 590:437-443

6. Otto C, Sonnichsen AC, Ritter MM, Richter WO, Schwandt P (1993) Influence of fiber, xylitol and fructose in enteral formulas on glucose and lipid metabolism in normal subjects. Clin Investig 71:290-293
7. Govindasamy C, Al-Numair KS, Alsaif MA, Viswanathan KP (2011) Influence of 3-hydroxymethyl xylitol, a novel antidiabetic compound isolated from Casearia esculenta (Roxb.) root, on glycoprotein components in streptozotocin-diabetic rats. J Asian Nat Prod Res 13:700-706

8. Amo K, Arai H, Uebanso T et al (2011) Effects of xylitol on metabolic parameters and visceral fat accumulation. J Clin Biochem Nutr 49:1-7

9. Liu YQ, Uyeda K (1996) A mechanism for fatty acid inhibition of glucose utilization in liver. Role of xylulose 5-P. J Biol Chem 271:8824-8830

10. Massillon D, Chen W, Barzilai N et al (1998) Carbon flux via the pentose phosphate pathway regulates the hepatic expression of the glucose-6-phosphatase and phosphoenolpyruvate carboxykinase genes in conscious rats. J Biol Chem 273:228-234

11. Argaud D, Lange AJ, Becker TC et al (1995) Adenovirus-mediated overexpression of liver 6-phosphofructo-2-kinase/fructose-2,6bisphosphatase in gluconeogenic rat hepatoma cells. Paradoxical effect on Fru-2,6-P2 levels. J Biol Chem 270:24229-24236

12. Boden G, Chen X, Ruiz J, White JV, Rossetti L (1994) Mechanisms of fatty acid-induced inhibition of glucose uptake. J Clin Invest 93:2438-2446

13. Boden G, Shulman GI (2002) Free fatty acids in obesity and type 2 diabetes: defining their role in the development of insulin resistance and beta-cell dysfunction. Eur J Clin Invest 32(Suppl 3):1423

14. Kishore P, Li W, Tonelli J et al (2010) Adipocyte-derived factors potentiate nutrient-induced production of plasminogen activator inhibitor-1 by macrophages. Sci Transl Med 2:20ra15

15. Steinberg LM, Odusola F, Mandel ID (1992) Remineralizing potential, antiplaque and antigingivitis effects of xylitol and sorbitol sweetened chewing gum. Clin Prev Dent 14:31-34 